\title{
A Flexible and Compact Semicircular Antenna for Multiple Wireless Communication Applications
}

\author{
Faiza AKHTAR ${ }^{1}$, Syeda Iffat NAQVI ${ }^{1}$, Farzana ARSHAD ${ }^{1}$, Yasar AMIN ${ }^{1,2}$, Hannu TENHUNEN ${ }^{2,3}$ \\ ${ }^{1}$ ACTSENA Research Group, University of Engineering and Technology (UET), Taxila, 47050, Pakistan \\ ${ }^{2}$ iPack VINN Excellence Center, Royal Institute of Technology (KTH), SE-16440, Stockholm, Sweden \\ ${ }^{3}$ TUCS, University of Turku, Turku-20520, Finland
}

Iffat.naqvi@uettaxila.edu.pk, faizaakhtar1993@yahoo.com

Submitted January 5, 2018 / Accepted May 21, 2018

\begin{abstract}
This work presents a compact, quad-band planar antenna intended for assimilation into flexible and conformal devices. The CPW-fed semicircular shaped prototype with rake-shaped slots is designed, realized and characterized experimentally. The frequency bands covered by the proposed radiator are centered at 2.5, 3.7, 5.5 and $8 \mathrm{GHz}$ with measured impedance bandwidths of $16 \%$, $13.5 \%, 11.8 \%$ and $14.63 \%$, respectively. The proposed antenna is thus enabled to support WLAN, ISM, Bluetooth, WiMAX, LTE and X-band applications. The antenna exhibits a significant gain. The radiation characteristics of the proposed radiator are measured in concave and convex bent shapes at various radii to analyze its flexibility. Performance of the antenna remains almost unaffected in the bent situation. Measurements demonstrate good coherence with simulations. The compactness and good performance of the design both in bent and unbent conditions proves it to be the better contender for future multiband conformal wireless applications.
\end{abstract}

\section{Keywords}

Quad-band, CPW-feedline, flexible substrate, WLAN, WiMAX

\section{Introduction}

Microstrip patch antennas, because of their captivating aspects such as low profile, simple realization, and concurrence with planar monolithic microwave integrated circuit (MMIC) components, have been found the desirable type of antennas used for wireless communication systems. Modern typical portable devices are desired to operate at WLAN, Bluetooth, 2G, 3G, 4G and GPS standards. Consequently, it is required to integrate as many standards as possible on a single wireless device. In addition to this, the antennas that are integrated into handheld wireless devices need to be compact, lightweight, easy to fabricate and flexible.
Many different antennas have been reported in the literature with the ability to operate at multiple frequency bands [1-8]. However, these multi-frequency radiators do not meet the conformal requirements as they were realized on a rigid and thick substrate like FR-4. Antennas presented in [1-3] are triple band rigid antennas with large geometrical dimensions. Prototype presented in [4] is a large hexaband antenna. Quad-band antennas have also been reported [5-8] exhibiting larger dimensions thus deficient in the required compactness.

Recently, flexible substrates such as paper and polymers have witnessed great progress because of their appealing characteristics of being cheaper, lightweight and more environment friendly in fabrication processing and disposal in addition to their flexible feature. Due to these advantages, numerous antennas with flexible substrates have been reported. A flexible bow-tie antenna with dual band operation and overall geometrical size of $80 \times 60 \mathrm{~mm}^{2}$ is reported [9]. In [10], a single band flexible textile antenna with comparatively large geometry is realized on $2 \mathrm{~mm}$ thick substrate for $2.45 \mathrm{GHz}$ body area networks. The analysis of the radiator in bent condition has also been carried out. A dual-band inkjet printed multiband antenna on paper substrate with compact dimensions of $10 \times 37.3 \times 0.44 \mathrm{~mm}^{3}$ is reported [11]. However, the flexibility analysis has not been taken into account. In [12] a compact polyamide substrate based radiator is proposed with dimensions of $24 \times 24 \mathrm{~mm}^{2}$ for WLAN applications but the antenna does not exhibit multiband operation. Similarly an inkjet printed multiband antenna on thin flexible substrate Kapton with geometrical size of $70 \times 70 \mathrm{~mm}^{2}$ is reported [13]. Flexibility aspect of the iterative radiator is also analyzed. A CPW-fed quad-band radiator with overall geometry of $90 \times 60 \mathrm{~mm}^{2}$ is presented [14] to operate at four frequency bands. The radiator is realized on flexible Rogers RT/Duroid 5880 substrate with $0.127 \mathrm{~mm}$ thickness and the performance in bent situation has also been investigated. In [15] an elliptical dual band, monopole antenna with geometric size of $48 \times 33 \mathrm{~mm}^{2}$ and fabricated on flexible $0.13 \mathrm{~mm}$ thick Kapton substrate is reported. The performance analysis in deformed and bent configurations 
has been carried out. An inkjet printed triple band antenna realized on resin coated paper substrate with overall dimensions of $35 \times 40 \mathrm{~mm}^{2}$ is proposed in [16]. The work in [17] presents a proximity coupled-fed microstrip flexible antenna with overall geometry of $40 \times 40 \mathrm{~mm}^{2}$ and dual band operation. In [18] a flexible antenna for Rogers RT/Duroid 5880 with thickness of $0.127 \mathrm{~mm}$ have been reported but it is not multiband. It has been observed from previously reported work that a compromise between antenna size and number of frequency bands achieved exists at all times.

In this article, a compact flexible quad-band antenna with CPW feed line is presented. The overall geometrical size of the prototype is $24 \times 24 \mathrm{~mm}^{2}$ and is realized on flexible Rogers RT/Duroid 5880 substrate with $0.127 \mathrm{~mm}$ thickness. Circular patch is considered as one of the most popular patch antennas. It took a lot of attention by the researchers as a single element and array, too. Unlike the rectangular patch, a circular patch has only one dimension to control. The proposed radiator can achieve the advantage of purposed size reduction and ease of fabrication due to the planar configuration. Likewise, CPW feed allows the antenna to integrate with other microwave circuits and RF devices. The presented antenna covers frequency bands of 2.2-2.6, 3.4-3.9, 5.15-5.8, and 7.3-8.5 GHz, respectively thus supporting WLAN, ISM, Bluetooth, WiMAX, LTE and X-band applications.

\section{Antenna Design and Working Mechanism}

The important parameters are taken into consideration while designing the patch antennas such as resonant frequency, dielectric constant, thickness of the substrate and the shape of the radiator/patch. Figure 1 illustrates the layout of the presented antenna. Aiming at the objectives of impedance matching and achieving maximum gain for the desired bands, the antenna incorporates a semicircular slotted patch with semicircular ground and a $50 \Omega$ coplanar waveguide $(\mathrm{CPW})$ feedline. The radius of the patch based on the resonant frequency is calculated using the following equations [19].

$$
\begin{gathered}
a=\frac{F}{\left\{1+\frac{2 h}{\pi \varepsilon_{\mathrm{r}} F}\left[\ln \left(\frac{\pi F}{2 h}\right)+1.7726\right]\right\}^{1 / 2},} \\
F=\frac{8.791 \times 10^{9}}{f_{\mathrm{r}} \sqrt{\varepsilon_{\mathrm{r}}}}, \\
a_{\mathrm{e}}=a\left\{1+\frac{2 h}{\pi a \varepsilon_{\mathrm{r}}}\left[\ln \left(\frac{\pi a}{2 h}\right)+1.7726\right]\right\}^{1 / 2}, \\
\left(f_{\mathrm{rc}}\right)_{110}=\frac{1.8412 v_{\mathrm{o}}}{2 \pi a_{\mathrm{e}} \sqrt{\varepsilon_{\mathrm{r}}}}
\end{gathered}
$$

where $a$ is the radius of the circular patch, $h$ is the substrate height, $\varepsilon_{\mathrm{r}}$ is relative permittivity of the substrate and $f_{\mathrm{r}}$ is the resonant frequency. The antenna with overall dimensions of $24 \times 24 \mathrm{~mm}^{2}$ is realized on flexible Rogers RT/Duriod 5880 substrate with thickness, $h=0.127 \mathrm{~mm}$, $\varepsilon_{\mathrm{r}}=2.2$ and $\delta=0.0009$. The elementary geometry of the proposed circular patch antenna is designed for $2.5 \mathrm{GHz}$ resonant frequency using CST ${ }$ MWS $\AA$. By using all these parameters the radius $\mathrm{R} 1$ of the circular patch is calculated and found to be $11 \mathrm{~mm}$. Table 1 further elaborates the dimensions of the proposed design.

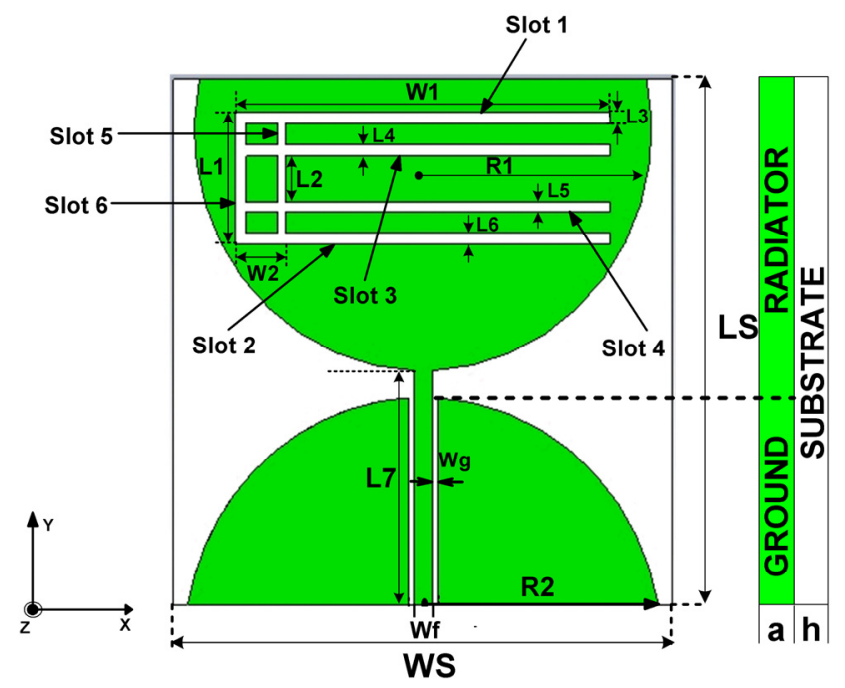

Fig. 1. Geometric dimensions of the proposed prototype.

\begin{tabular}{|c|c|c|c|}
\hline Parameter & Size(mm) & Parameter & Size(mm) \\
\hline $\mathrm{L}_{\mathrm{S}}$ & 24 & $\mathrm{Ws}$ & 24 \\
\hline $\mathrm{L}_{1}$ & 6 & $\mathrm{~W}_{1}$ & 18 \\
\hline $\mathrm{L}_{2}$ & 2.1 & $\mathrm{~W}_{2}$ & 2.4 \\
\hline $\mathrm{L}_{3}, \mathrm{~L}_{4}, \mathrm{~L}_{6}$ & 0.5 & $\mathrm{~W}_{\mathrm{f}}$ & 1 \\
\hline $\mathrm{L}_{5}$ & 0.4 & $\mathrm{R}_{2}$ & 11.5 \\
\hline $\mathrm{L}_{7}$ & 10.7 & $\mathrm{a}$ & 0.035 \\
\hline $\mathrm{R}_{1}$ & 11 & $\mathrm{~h}$ & 0.127 \\
\hline
\end{tabular}

Tab. 1. Optimized dimensions of the proposed antenna.

Figure 2(a) clearly illustrates the evolution of the design proposed in this work. For better understanding of the mechanism adopted to develop the model, the return loss $\left(S_{11}\right)$ for the four design stages is plotted in Fig. 2 (b).

Initially, Antennal is designed as a basic semicircular patch of radius $\mathrm{R} 1$ with $\mathrm{CPW}$ feedline of width $\mathrm{W}_{\mathrm{f}}$. The ground is also semicircular with radius $\mathrm{R} 2$. This primary structure is designed to resonate at $2.5 \mathrm{GHz}$ frequency with $S_{11}<-10 \mathrm{~dB}$, as shown in Fig. 2(b). Antenna2 is modeled by subtracting two horizontal slots $1 \& 2$ from the semicircular patch of Antenna1. This generates two additional resonances at $5.8 \mathrm{GHz}$ and $8.3 \mathrm{GHz}$. In the third step, a vertical slot 5 of width $0.4 \mathrm{~mm}$ and a horizontal slot 3 are withdrawn. Due to the mutual coupling between the slots, 
the previously obtained resonances at 5.8 and $8.3 \mathrm{GHz}$ improve and shift to 5.7 and $8 \mathrm{GHz}$ respectively for Antenna3. The frequency shift at $2.5 \mathrm{GHz}$ band is negligible while another narrow band at $3.6 \mathrm{GHz}$ is also achieved. Finally proposed antenna is achieved by subtracting horizontal slot 4 and vertical slot 6 . By incorporating these two slots, resonant frequencies attained at 3.6 and $5.7 \mathrm{GHz}$ are shifted to 3.7 and $5.5 \mathrm{GHz}$, whereas a slight improvement in bandwidth has been found for the $2.5 \mathrm{GHz}$ and $8 \mathrm{GHz}$ frequency bands. The impedance bandwidth at $3.7 \mathrm{GHz}$ is also improved from $200 \mathrm{MHz}(3.5-3.7 \mathrm{GHz})$ to $500 \mathrm{MHz}$ $(3.3-3.8 \mathrm{GHz})$. Thus, the final radiating structure with optimum results has been obtained. This final proposed design delivers four resonances at $2.5,3.7,5.5$ and $8 \mathrm{GHz}$ supporting 2.4/5.2/5.5 GHz WLAN, 2.5/3.5 GHz WiMAX [20], LTE 2300/2500, ISM, Bluetooth and X-band applications.

The working mechanism of the proposed multiband antenna can be better demonstrated by analyzing surface current distribution at four resonant frequencies, i.e. 2.5, 3.7, 5.5 and $8 \mathrm{GHz}$ as depicted in Fig. 3(a)-3(d). Figure 3(a) shows current is mainly concentrated at the feedline and the outer edges of the circular patch for $2.5 \mathrm{GHz}$. While for $3.7 \mathrm{GHz}$, the current density is widely observed at vertical slot 5, as illustrated in Fig. 3(b). Similarly, it is evident from Fig. 3(c) that major current distribution is seen on vertical slots and horizontal slot $1 \& 2$ for $5.5 \mathrm{GHz}$ resonance. For $8 \mathrm{GHz}$ resonant frequency, the major density of current is observed on vertical slot 6 and horizontal slots, as clearly shown in Fig. 3(d).
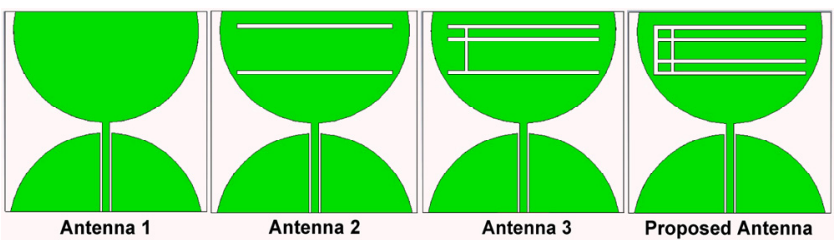

(a)

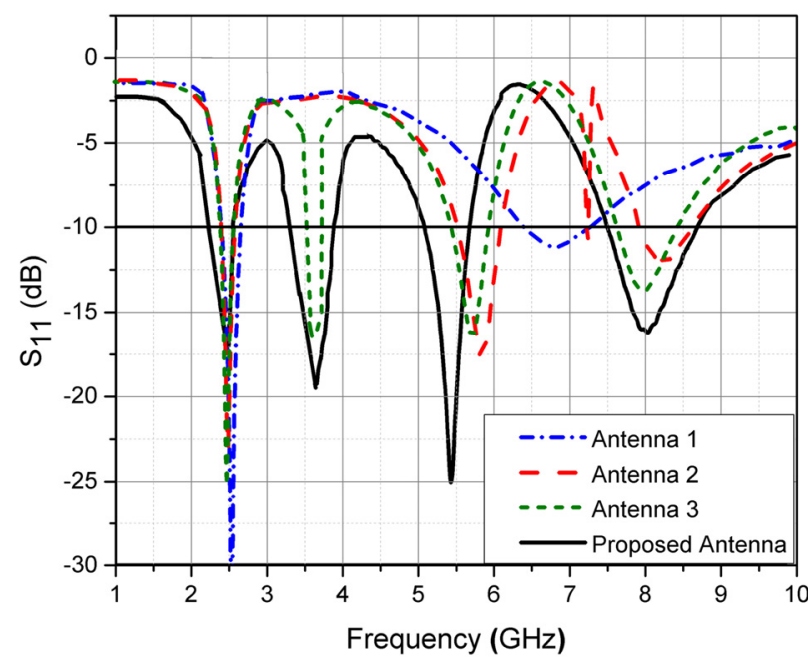

(b)

Fig. 2. (a) Evolution stages of the antenna. (b) Resultant $S_{11}$.

\section{Results and Discussion}

According to the optimal values of the prototype as provided in Tab. 1, the quad-band antenna is fabricated and measured to endorse the performance. Measured results are obtained by the R\&S®ZVL13 Vector Network Analyzer. The fabricated prototype in different configurations is shown in Fig. 4.

Figure 5 illustrates simulated and measured return loss showing good coherence. The obtained commercial bands and respective bandwidth of each band are summarized in Tab. 2. The first considerable frequency band with $S_{11}<-10 \mathrm{~dB}$ is $2.25-2.55 \mathrm{GHz}$ with $16 \%$ impedance bandwidth covering the WLAN, WiMAX, LTE 2300/2500, Bluetooth and ISM bands. The second and third bands with $13.5 \%$ and $11.8 \%$ of bandwidth respectively, are suitable for the Fixed \& Mobile WiMAX as well as WLAN applications. The fourth band supports X-band applications with $14.63 \%$ impedance bandwidth. Good coherence is observed between measured and simulated results; however, insignificant differences are due to the unavoidable use of coaxial cable and SMA connector for measurement [21], [22].
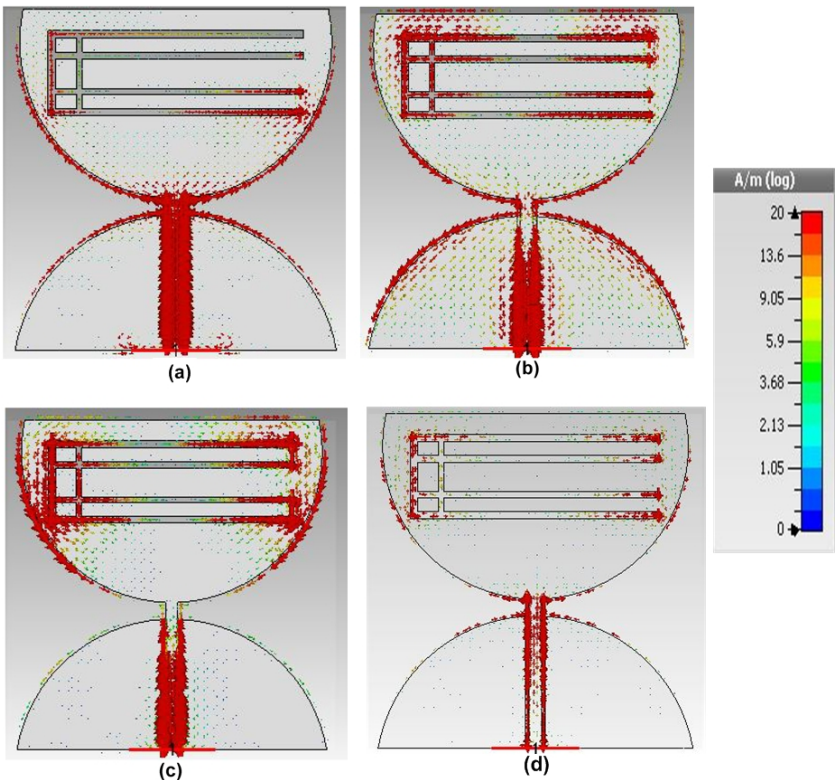

Fig. 3. Surface current density at: (a) $2.5 \mathrm{GHz}$, (b) $3.7 \mathrm{GHz}$, (c) $5.5 \mathrm{GHz}$, (d) $8 \mathrm{GHz}$.

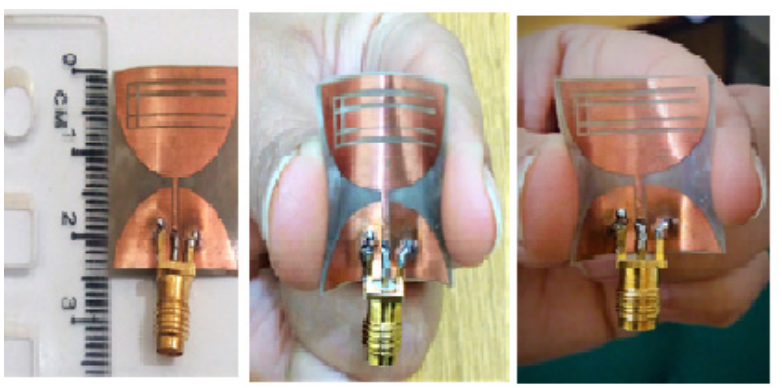

Fig. 4. Fabricated antenna in planar, convex and concave configuration. 


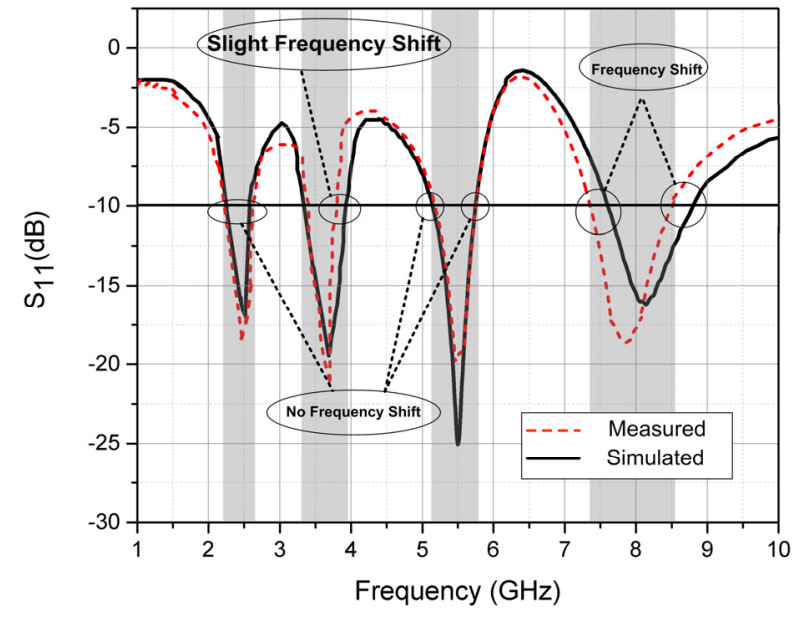

Fig. 5. Simulated and measured return loss $\left(\mathrm{S}_{11}\right)$.

The simulated and measured gain for each acquired band of the presented radiator is depicted in Fig. 6. The gain values are $1.7,0.7,3.8$ and $2.1 \mathrm{~dB}$ for $2.5,3.7,5.5$ and $8 \mathrm{GHz}$ resonant frequencies, respectively. The gain for some resonant frequencies is low due to CPW feedline. As there is no ground on the other side, the patch antenna starts to radiate at other directions. Consequently the radiated power is distributed over a large area reducing gain. In the proposed work maximum achieved radiation efficiency is $76 \%$. Table 3 summarizes the radiation efficiency and gain comparisons of the proposed antenna for each band.

\begin{tabular}{|c|c|c|}
\hline $\begin{array}{c}\text { Band } \\
\text { No. }\end{array}$ & Bandwidth & Obtained commercial bands \\
\hline & & WLAN (2400-2480 MHz), \\
& $\begin{array}{c}2.25-2.55 \mathrm{GHz} \\
(300 \mathrm{MHz})\end{array}$ & $\begin{array}{c}\text { LTE } 2300(2305-2400 \mathrm{MHz}), \\
\text { LTE } 2500(2500-2690 \mathrm{MHz}) \\
\text { ISM \& Bluetooth }(2400-2480 \mathrm{MHz}), \\
\text { WiMAX (2500-2690 MHz) }\end{array}$ \\
\hline $\mathbf{2}$ & $\begin{array}{c}3.4-3.8 \mathrm{GHz} \\
(400 \mathrm{MHz})\end{array}$ & $\begin{array}{c}\text { Fixed \& Mobile WiMAX } \\
(3600-3800 \mathrm{MHz})\end{array}$ \\
\hline $\mathbf{3}$ & $\begin{array}{c}5.2-5.75 \mathrm{GHz} \\
(550 \mathrm{MHz})\end{array}$ & $\begin{array}{c}\text { WLAN } \\
(5150-5350 \mathrm{MHz}, 5470-5725 \mathrm{MHz})\end{array}$ \\
\hline $\mathbf{4}$ & $\begin{array}{c}7.4-8.5 \mathrm{GHz} \\
(1100 \mathrm{MHz})\end{array}$ & X-band applications \\
\hline
\end{tabular}

Tab. 2. Achieved frequency bands with respective bandwidth.

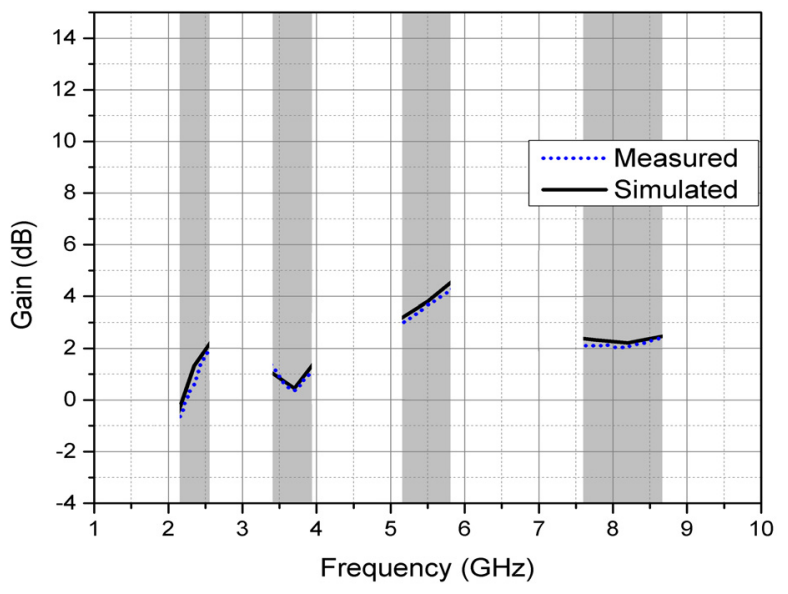

Fig. 6. Simulated and measured gain.

\begin{tabular}{|c|c|c|c|c|}
\hline Frequency & $\mathbf{2 . 5} \mathbf{~ G H z}$ & $\mathbf{3 . 7} \mathbf{~ G H z}$ & $\mathbf{5 . 5} \mathbf{~ G H z}$ & $\mathbf{8 ~ G H z}$ \\
\hline $\begin{array}{c}\text { Simulated } \\
\text { Gain (dB) }\end{array}$ & 1.8 & 0.8 & 3.99 & 2.2 \\
\hline $\begin{array}{c}\text { Measured } \\
\text { Gain(dB) }\end{array}$ & 1.7 & 0.7 & 3.8 & 2.1 \\
\hline $\begin{array}{c}\text { Radiation } \\
\text { Efficiency }\end{array}$ & $63 \%$ & $62 \%$ & $76 \%$ & $65 \%$ \\
\hline
\end{tabular}

Tab. 3. Comparison between simulated and measured gain.

Figure 7(a)-7(d) exhibits simulated and measured radiation patterns for both E-plane(y-z) and H-plane(x-z) at $2.5,3.7,5.5$ and $8 \mathrm{GHz}$ for unbent configuration. In E-plane the bi-directional radiation patterns have been obtained while for the H-plane, an omni-directional behavior has been detected. Thus, the monopole-like response has been acquired. Hence, it is evident from the radiation characteristics that the antenna shows a steady response for the attained operating bandwidth.

\section{Flexibility Analysis}

Flexible antennas are substantial components for current and future wireless applications, comprising sensor systems and wearable on-body applications. There is always a compromise between attaining conformability and low cost. For flexible antennas, compact size and good radiation parameters with performance maintained throughout bending are the key design objectives. However, the performance of the antenna could be affected when converting from planar to bent configuration depending on the geometry, substrate material, and other factors. In this work, the bending affect of the antenna is investigated at three different angles $50^{\circ}, 28.6^{\circ}$, and $21^{\circ}$ with 27,48 , and $65 \mathrm{~mm}$ radii respectively. As the cylinder is used as the reference structure of the antenna for bending purpose, the outer radius of the cylinder is calculated using

$$
S=r \theta
$$

where $S$ is the arc length, $r$ is the radius of the circle and $\theta$ is the measure of the central angle in radians. Analysis of reflection coefficient and radiation characteristics of the antenna in convex and concave positions with three different radii has been done using CST ${ }^{\circledR} M W S \circledR$ simulator. Keeping in view the requirements and bending abilities for upcoming flexible wireless devices, a radius of $65 \mathrm{~mm}$ is selected to investigate flexibility for both convex and concave formations and reflection coefficient is then measured. The antenna in bent form is illustrated in Fig. 8.

Figure 9(a), (b). illustrates the simulated and measured reflection coefficient $\left(\mathrm{S}_{11}\right)$ of the radiator at three diverse radii in convex and concave bent positions as well as in the unbent configuration. In case of convex bending no noteworthy deprivation is witnessed, except a minor shifting of the first band band $(2.25-2.55 \mathrm{GHz})$ to 2.35-2.55 GHz. While for the concave configuration an insignificant shifting of the resonant frequency of the second band from $3.7 \mathrm{GHz}$ to $3.8 \mathrm{GHz}$ is observed. The primary reason behind this is the bending of the outer edges 

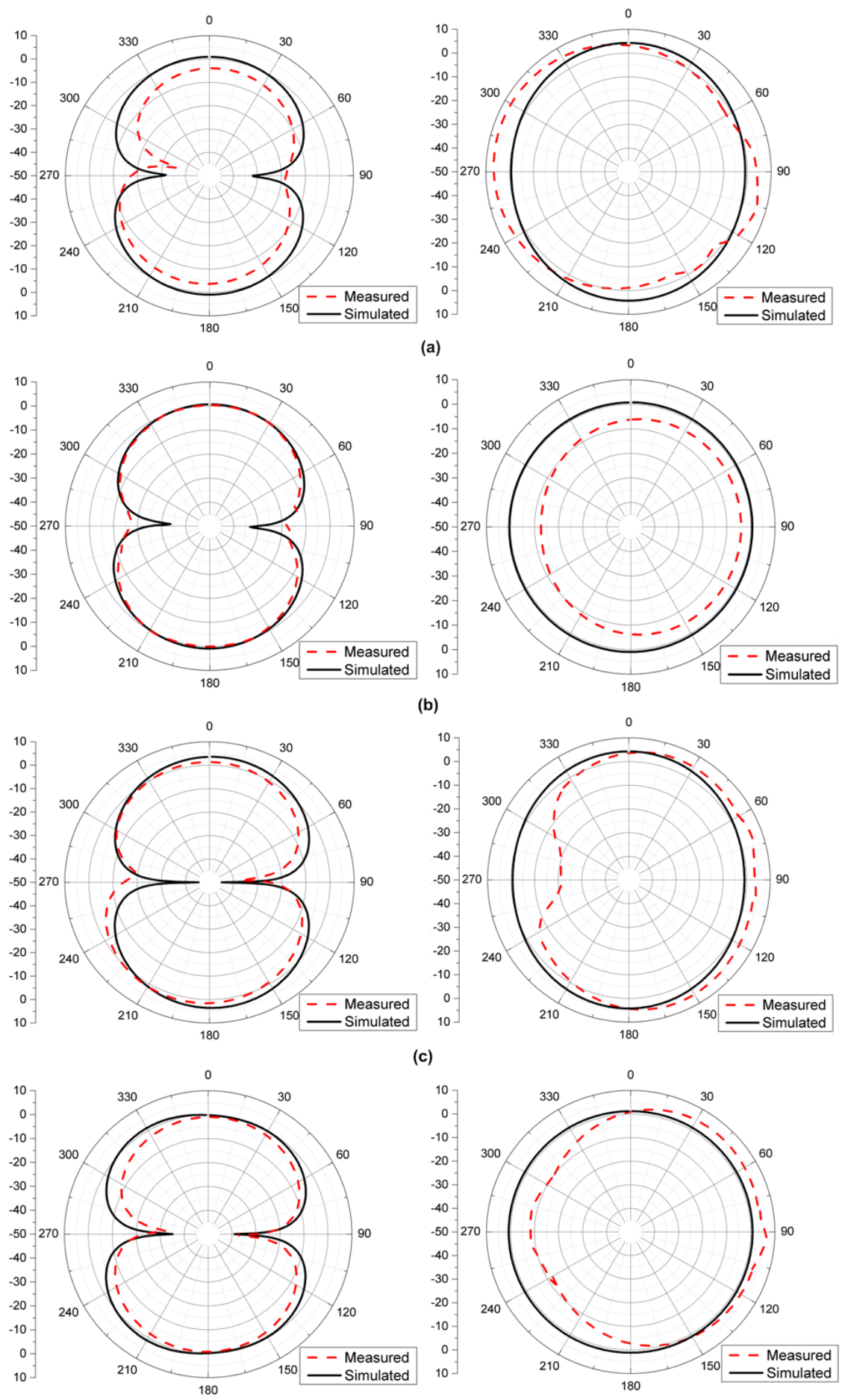

(d)

Fig. 7. Simulated and measured radiation patterns of the antenna at: (a) $2.5 \mathrm{GHz}$, (b) $3.7 \mathrm{GHz}$, (c) $5.5 \mathrm{GHz}$, (d) $8 \mathrm{GHz}$.

of the patch and vertical slots. Trivial narrowing of the band is found for the first band while impedance matching is enhanced for upper-frequency bands.

Figure 10 depicts the measured and simulated radiation patterns at $2.5 \mathrm{GHz}$ and $5.5 \mathrm{GHz}$ in both convex and concave configuration for different radii respectively. Measurements exhibit decent agreement with simulations. The gain correlation with and without bending is provided in Tab. 4. For convex bent form, an increment of $0.2 \mathrm{~dB}$ and $0.34 \mathrm{~dB}$ in gain is noticed for the resonant frequencies at $3.7 \mathrm{GHz}$ and $5.5 \mathrm{GHz}$ respectively for $65 \mathrm{~mm}$. Likewise, in concave bent shape, an absolute rise of $0.33,0.14$ and $0.08 \mathrm{~dB}$ is observed in the $3.7,5.5$ and $8 \mathrm{GHz}$ frequency bands, respectively. The principal reason for this realized alteration in gain is the trivial rise in the directivity of the antenna for bent configurations. The good robustness determines the capability of the proposed design for forthcoming flexible devices. Comparative analyses of the several previously reported works with the proposed quad- 


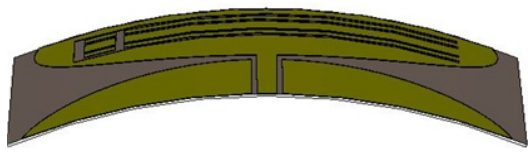

(a)

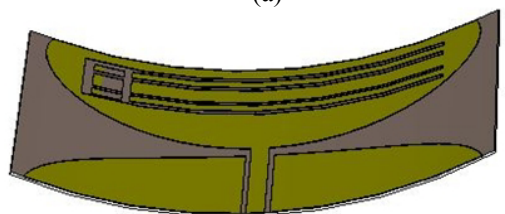

(b)

Fig. 8. (a) Convex bending. (b) Concave bending.

\begin{tabular}{|c|c|c|c|c|}
\hline \multicolumn{3}{|c|}{ Convex configuration } & \multicolumn{2}{c|}{ Concave configuration } \\
\hline $\begin{array}{l}\text { Band } \\
\text { No. }\end{array}$ & $\begin{array}{c}\text { Without } \\
\text { bending }\end{array}$ & $\begin{array}{c}\text { With } \\
\text { bending at } \\
\text { R1= 65 } \mathbf{~ m m}\end{array}$ & $\begin{array}{c}\text { Without } \\
\text { bending }\end{array}$ & $\begin{array}{c}\text { With } \\
\text { bending at } \\
\text { R1 = 65 } \mathbf{~ m m}\end{array}$ \\
\hline $\mathbf{1}$ & 1.7 & 1.44 & 1.7 & 1.46 \\
\hline $\mathbf{2}$ & 0.7 & 0.909 & 0.7 & 1.03 \\
\hline $\mathbf{3}$ & 3.8 & 4.14 & 3.8 & 3.94 \\
\hline $\mathbf{4}$ & 2.1 & 1.67 & 2.1 & 2.18 \\
\hline
\end{tabular}

Tab. 4. Gain comparison of the antenna for unbent and bent configuration.

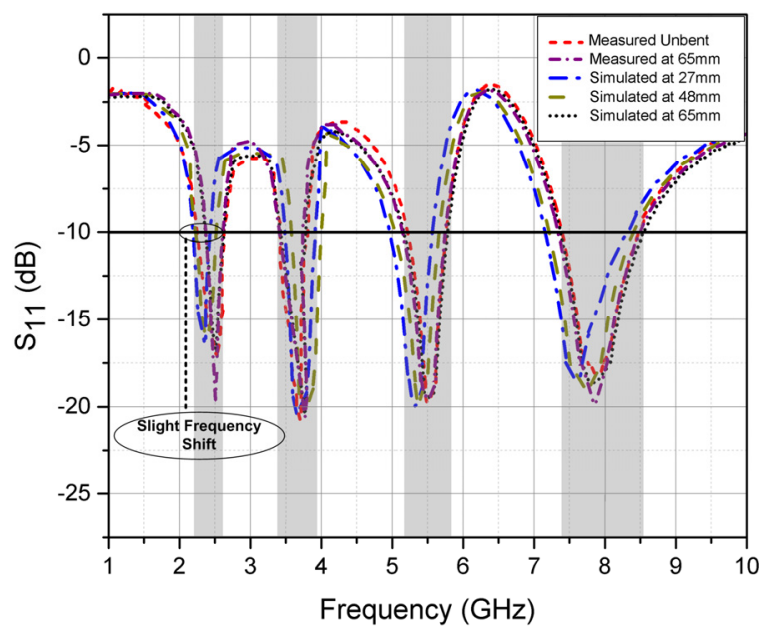

(a)

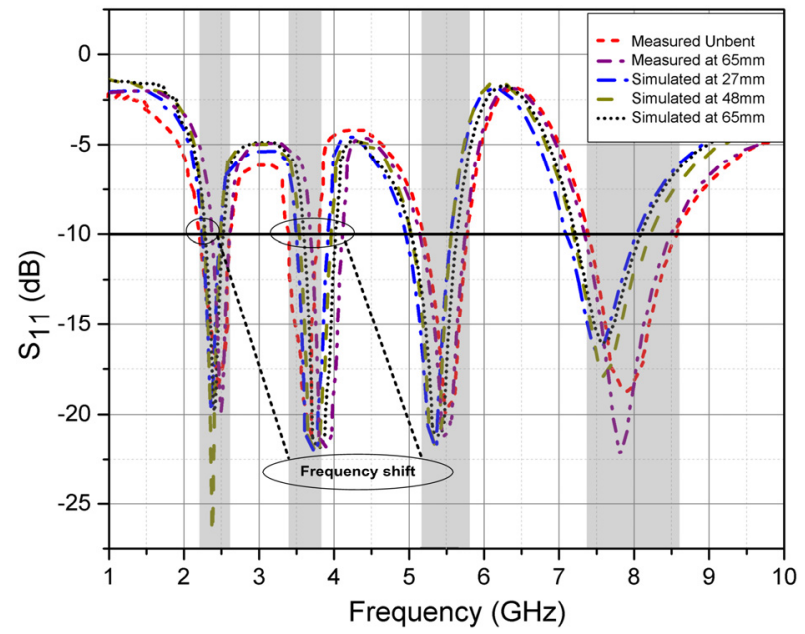

(b)

Fig. 9. Measured and simulated reflection coefficient $\left(S_{11}\right)$ of the antenna for (a) convex and (b) concave bending.

\begin{tabular}{|c|c|c|c|}
\hline Ref. & Size & $\begin{array}{c}\text { Maximum } \\
\text { gain(dB) }\end{array}$ & $\begin{array}{c}\text { Bands } \\
\text { obtained }\end{array}$ \\
\hline$[9]$ & $80 \mathrm{~mm} \times 60 \mathrm{~mm}$ & $6.20 \mathrm{dBi}$ & 3 \\
\hline$[13]$ & $70 \mathrm{~mm} \times 70 \mathrm{~mm}$ & $2.1 \mathrm{dBi}$ & 4 \\
\hline$[134$ & $90 \mathrm{~mm} \times 60 \mathrm{~mm}$ & $5.88 \mathrm{dBi}$ & 4 \\
\hline $\begin{array}{c}\text { Proposed } \\
\text { Work }\end{array}$ & $\mathbf{2 4} \mathbf{~ m m} \times \mathbf{2 4} \mathbf{~ m m}$ & $\mathbf{3 . 8} \mathbf{d B i}$ & $\mathbf{4}$ \\
\hline
\end{tabular}

Tab. 5. Comparison between earlier reported flexible antennas.

band antenna has been presented in Tab. 5. It is evident that the obtained compact radiator exhibits good performance.

\section{Conclusion}

In this work, a compact and flexible semicircular antenna with the quad-band operation is exhibited with meticulous simulated and measured results. The rake- shaped slots generate resonances at $2.5,3.7,5.5$, and $8 \mathrm{GHz}$ and thus provide support for WLAN, WiMAX, LTE 2300/2500, ISM, Bluetooth and X-band applications. An insignificant shift in resonant frequency is revealed for convex bending, whereas no substantial variation is experienced for concave bending. An omnidirectional radiation pattern is obtained for the proposed prototype. The measured results reveal a maximum of 3.8 and $4.14 \mathrm{~dB}$ gain in unbent and bent configurations, respectively. Good radiation characteristics, as well as the robustness of the proposed design, demonstrate the appropriateness of the antenna for forthcoming flexible and conformal electronic devices.

\section{Acknowledgment}

This work was financially supported by Vinnova (The Swedish Governmental Agency for Innovation Systems) and UET Taxila, Pakistan through the Vinn Excellence Centers Program and ACTSENA Research Group Funding, respectively.

\section{References}

[1] LI, D., MAO, J.-F. Coplanar waveguide-fed-Koch-like sided Sierpinski hexagonal carpet multifractal monopole antenna. IET Microwaves, Antennas \& Propagation, 2014, vol. 8, no. 5, p. 358 to 366. DOI: 10.1049/iet-map.2013.0041

[2] WU, R.-Z., WANG, P., ZHENG, Q., et al. Compact CPW-fed triple band antenna for diversity applications. Electronics Letters, 2015, vol. 51, no. 10, p. 735-736. DOI: 10.1049/el.2015.0466

[3] LIU, G., FANG, M., ZHI, R., et al. Compact CPW-fed multiband antenna for TD-LTE/WLAN/WiMAX applications. Progress In Electromagnetics Research Letters, 2017, vol. 65, p. 9-14. DOI: 10.2528/PIERL16102203 

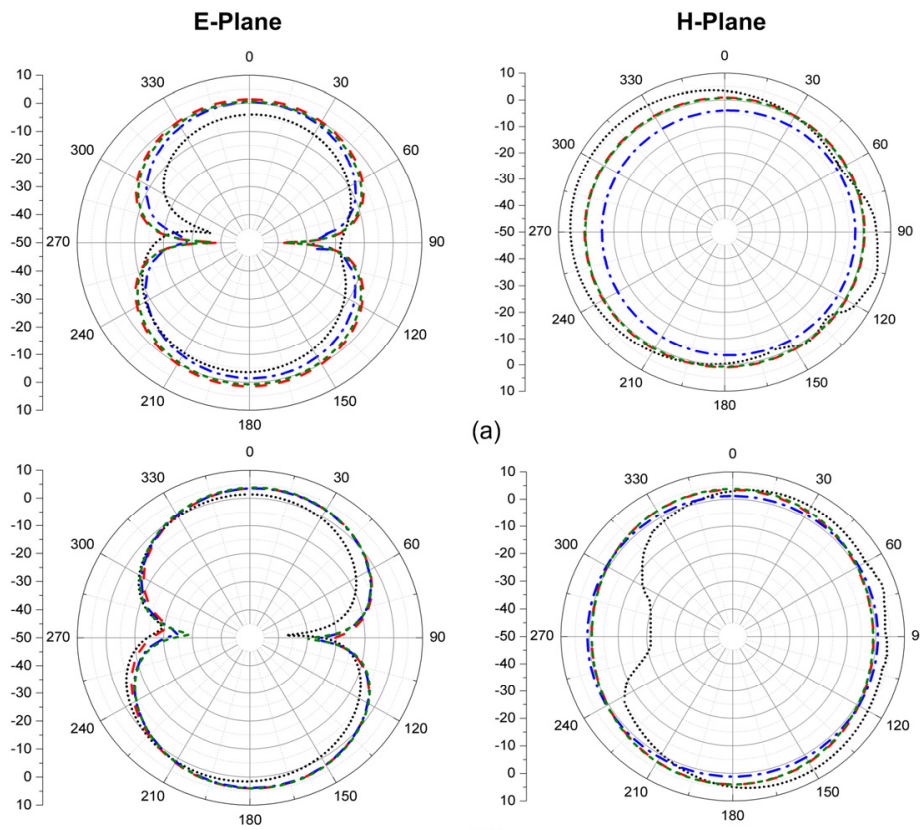

(a)
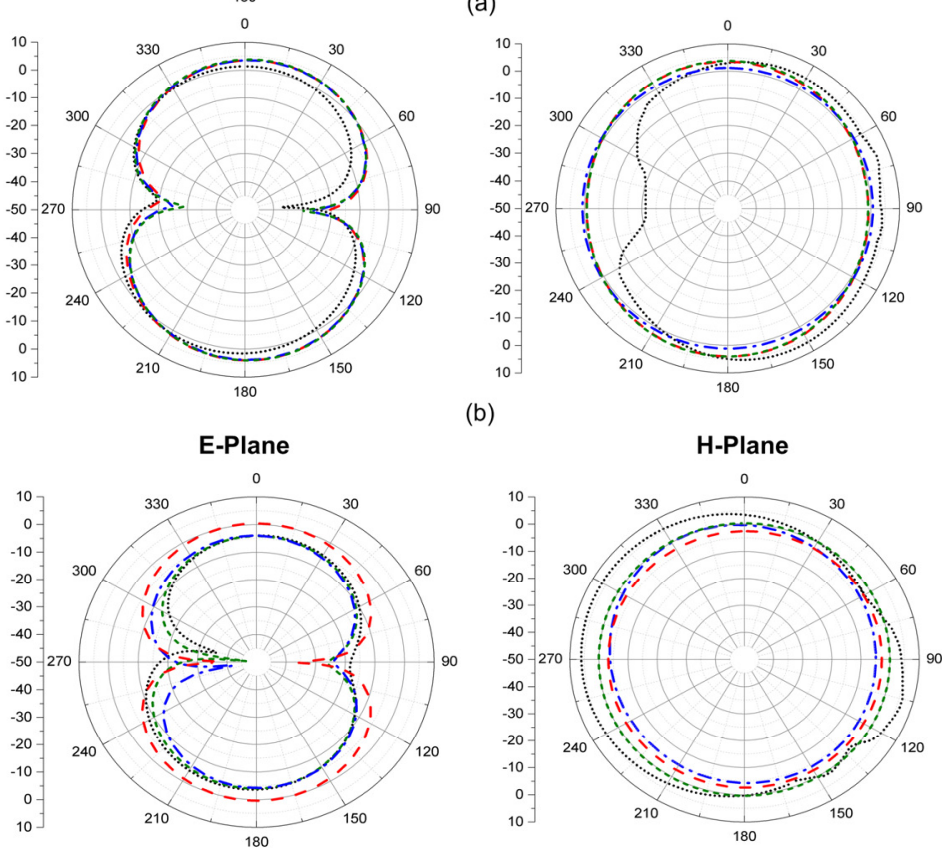

(b)
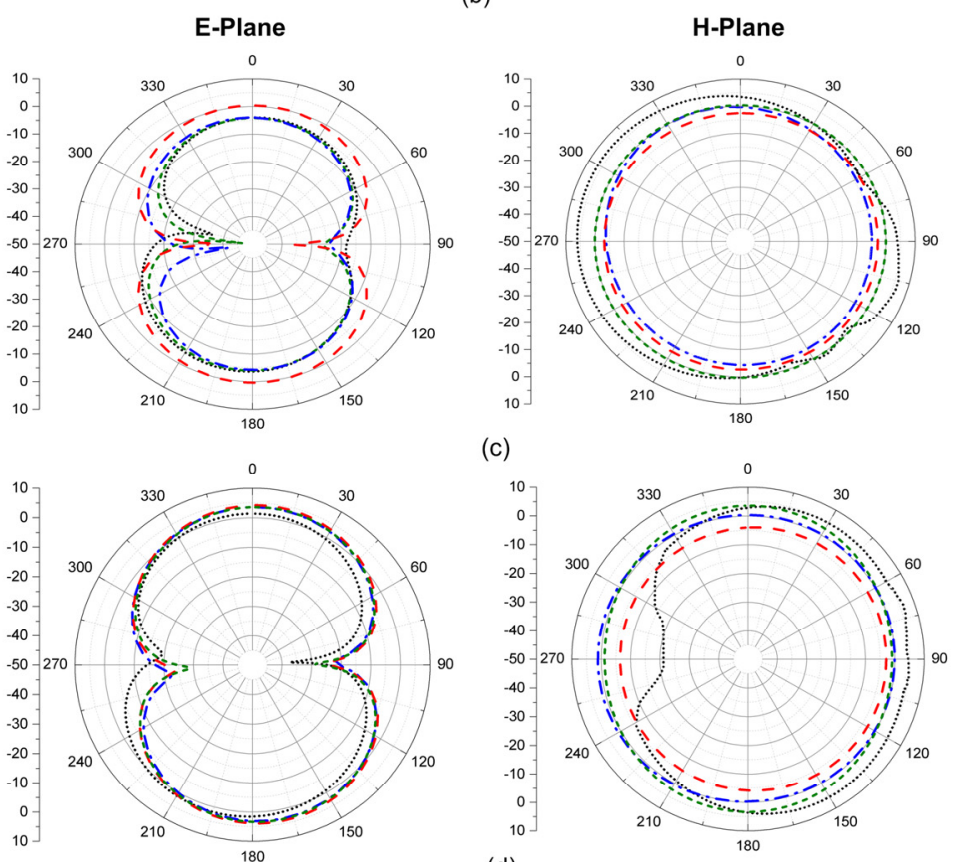

(d)

Measured Unbent - - - - Measured at $65 \mathrm{~mm}-\cdots$ - -Simulated at $65 \mathrm{~mm}-\quad-$ Simulated at $27 \mathrm{~mm}$

Fig. 10. Simulated and measured radiation patterns of convex bent at (a) $2.5 \mathrm{GHz}$, (b) $5.5 \mathrm{GHz}$ and concave bent at (c) $2.5 \mathrm{GHz}$, (d) $5.5 \mathrm{GHz}$.

[4] JAYASINGHE, J. W., ANGUERA, J., UDUWAWALA, D. N. A simple design of multiband microstrip patch antennas robust to fabrication tolerances for GSM, UMTS, LTE, and Bluetooth applications by using genetic algorithm optimizations. Progress in Electromagnetics Research, 2012, vol. 27, p. 255-269. DOI: 10.2528/PIERM12102705

[5] KHAN, A., NAQVI, S. I., ARSHAD, F., et al. A compact quadband CPW-fed planar resonator for multiple wireless communication applications. Applied Computational Electromagnetics Society Journal, 2017, vol. 32, no. 11, p. 1001-1007. ISSN: 1054-4887

[6] BOUKARKAR, A., LIN, X. Q., JIANG, Y., et al. Miniaturized single-feed multiband patch antennas. IEEE Transactions on Antennas and Propagation, 2017, vol. 65, no. 2, p. 850-854. DOI: 10.1109/TAP.2016.2632620
[7] CAO, Y. F., CHEUNG, S. W., YUK, T. I. A multiband slot antenna for GPS/WiMAX/WLAN systems. IEEE Transactions on Antennas and Propagation, 2015, vol. 63, no. 3, p. 952-958. DOI: 10.1109/TAP.2015.2389219

[8] CHEN, Y. J., LIU, T. W., TU, W. H. CPW-fed penta-band slot dipole antenna based on comb-like metal sheets. IEEE Antennas and Wireless Propagation Letters, 2017, vol. 16, p. 202-205. DOI: 10.1109/LAWP.2016.2569606

[9] SALLAM, M. O., KANDIL, S. M., VOLSKI, V., et al. Wideband CPW-fed flexible bow-tie slot antenna for WLAN/WiMAX systems. IEEE Transactions on Antennas and Propagation, 2017, vol. 65 , no. 8, p. 4274-4277. DOI: 10.1109/TAP.2017.2710227

[10] HU, B., GAO, G. P., HE, L. L., et al. Bending and on-arm effects 
on a wearable antenna for $2.45 \mathrm{GHz}$ body area network. IEEE Antennas and Wireless Propagation Letters, 2016, vol. 15, p. 378 to 381. DOI: 10.1109/LAWP.2015.2446512

[11] ABUTARboush, H. F., SHAMIM, A. Wide frequency independently controlled dual-band inkjet-printed antenna. IET Microwaves, Antennas \& Propagation, 2014, vol. 8, no. 1, p. 52-56. DOI: $10.1049 /$ iet-map.2013.0229

[12] LEE, C. M., KIM, Y., KIM, Y., et al. A flexible and transparent antenna on a polyamide substrate for laptop computers. Microwave and Optical Technology Letters, 2015, vol. 57, no. 5, p. 1038 to 1042. DOI: $10.1002 / \mathrm{mop}$

[13] AHMED, S., TAHIR, F. A., SHAMIM, A., et al. A compact kapton-based inkjet-printed multiband antenna for flexible wireless devices. IEEE Antennas and Wireless Propagation Letters, 2015, vol. 14, p. 1802-1805. DOI: 10.1109/LAWP.2015.2424681

[14] LIU, H., WEN, P., ZHU, S., et al. Quad-band CPW-fed monopole antenna based on flexible pentangle-loop radiator. IEEE Antennas and Wireless Propagation Letters, 2015, vol. 14, p. 1373-1376. DOI: 10.1109/LAWP.2015.2406391

[15] HAMOUDA, Z., WOJKIEWICZ, J.-L., PUD, A. A., et al. Dualband elliptical planar conductive polymer antenna printed on a flexible substrate. IEEE Transactions on Antennas and Propagation, 2015, vol. 63, no. 12, p. 5864-5867. DOI: 10.1109/TAP.2015.2479643

[16] Abutarboush, H. F., Farooqui, M. F., Shamim, A. Inkjet-printed wideband antenna on resin-coated paper substrate for curved wireless devices. IEEE Antennas and Wireless Propagation Letters, 2015, vol. 15, p. 20-23. DOI: 10.1109/LAWP.2015.2425797

[17] CASUlA, G. A., MAXIA, P., MONTISCI, G., et al. A multiband proximity-coupled-fed flexible microstrip antenna for wireless systems. International Journal of Antennas and Propagation, 2016, p. 1-7. DOI: $10.1155 / 2016 / 8536058$

[18] TANG, M.-C., SHI, T., ZIOLKOWSKI, R. W. Flexible efficient quasi-Yagi printed uniplanar antenna. IEEE Transactions on Antennas and Propagation, 2015, vol. 63, no. 12, p. 5343-5350. DOI: $10.1109 /$ TAP.2015.2486807

[19] BALANIS, C. A. Antenna Theory Analysis and Design. 3rd ed. Hoboken NJ (USA): John Wiley \& Sons, 2005. ISBN: 0-47166782-X

[20] CHAIMOOL, S., AKKARAEKTHALIN, P. Advanced Transmission Techniques in WiMAX. London (UK): InTech, 2012.(Ch. 2) ISBN: 978-953-307-965-3

[21] LIU, L., CHEUNG, S. W., WENG, Y. F., et al. Ultra WidebandCurrent Status and Future. London (UK): InTech, 2012. (Ch. 12) ISBN: 978-953-51-0781-1
[22] LIU, L., WENG, Y. F., CHEUNG, S. W., et al. Modeling of cable for measurements of small monopole antennas. In The $7^{\text {th }}$ Loughborough Antennas \& Propagation Conference (LAPC). Loughborough (UK), 2011, p. 1-4. DOI: 10.1109/LAPC.2011.6114153

\section{About the Authors...}

Faiza AKHTAR received her Bachelor's degree in Electrical (Telecommunication Engineering) from CIIT, Wah in 2016. Currently, she is enrolled as a Full time MS Scholar at the University of Engineering and Technology (UET), Taxila, Pakistan. Her research interests include planar and flexible multi-band antennas.

Syeda Iffat NAQVI is a part time Ph.D. Scholar in the UET Taxila, Pakistan. She is also a member of ACTSENA research group. Her current research interests include low profile flexible multiband antenna design. She is a member of IEEE and ACES.

Farzana ARSHAD is a part time Ph.D. researcher of ACTSENA group, UET Taxila. Her research focuses on low profile multi-band and reconfigurable antenna design.

Yasar AMIN is a Chairman and Associate Professor of Telecommunication Engineering Dept., UET Taxila, Pakistan. He is founder of ACTSENA Research Group at UET Taxila, Pakistan. He is a member of IEEE, IET, ACM and ACES.

Hannu TENHUNEN is a Chair Professor of Electronic Systems at the Royal Institute of Technology (KTH), Stockholm, Sweden. He has held professor position as full professor, invited professor or visiting honorary professor in Finland (TUT, UTU), Sweden (KTH), USA (Cornel U), France (INPG), China (Fudan and Beijing Jiatong Universities), and Hong Kong (Chinese University of Hong Kong), and has an honorary doctorate from Tallinn Technical University. He is a member of the Academy of Engineering Science of Finland. 